Home-based transabdominal interferential electrical stimulation for 6 months improves paediatric slow transit constipation (STC).

(4)

Yee lan Yik, MRCS, Ed, MS, PhD ${ }^{1,2,3}$; John Hutson, MD ${ }^{1,2,4}$; Bridget Southwell, BScHons, MSc, Phd $d^{1,2,4}$

${ }^{1}$ Gut Motility Laboratory, Douglas Stephens Surgical Research Group, Murdoch Children's

Research Institute, Royal Children's Hospital, Melbourne, Victoria, Australia;

${ }^{2}$ Department of Paediatrics, University of Melbourne, Melbourne, Victoria, Australia;

${ }^{3}$ Division of Paediatric and Neonatal Surgery, Department of Surgery, Faculty of Medicine, University of Malaya, 50603 Kuala Lumpur, MALAYSIA;

${ }^{4}$ Department of Urology, Royal Children's Hospital, Melbourne, Victoria, Australia

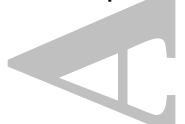

\title{
Authorship statement
}

Dr. Yee lan Yik performed the study under the supervision of Drs. Bridget Southwell and John Hutson. All authors contributed to the study design. Drs. Yee lan Yik and Bridget Southwell analysed the data. Drs. Bridget Southwell and John Hutson edited the manuscript, the final version of which was approved by all authors.

\section{Conflict of Interest:}

John Hutson and Bridget Southwell are members of an Advisory Committee for GI Therapies. Yee Ian Yik has no competing financial or other interests. Bridget Southwell and John Hutson have developed a new device to treat constipation, and have received government and investment funding for this purpose. The device is a prototype and was not used in this study. Bridget Southwell received consultancy fees from the start-up company, GI Therapies. Knowledge from this study was used in the design of the new device. Bridget Southwell and John Hutson have a patent for treatment of chronic constipation using transcutaneous electrical stimulation. Bridget Southwell has a design patent for a new device to treat constipation.

This is the author manuscript accepted for publication and has undergone full peer review but has not been through the copyediting, typesetting, pagination and proofreading process, which may lead to differences between this version and the Version record. Please cite this article as doi:10.1111/ ner.12734. 
Address correspondence to:

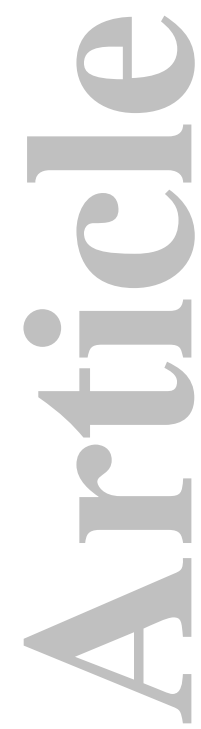

Dr Bridget Southwell

Surgical Group

Murdoch Children's Research Institute

Flemington Road

PARKVILLE, VICTORIA, 3052

Australia

Email: bridget.southwell@mcri.edu.au

Phone: 610393455805

Fax: $\quad 610393457997$

Key Words: paediatric, neuromodulation, interferential current, nuclear transit scintigraphy.

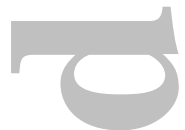

Running header: Home- Transabdominal stimulation for constipation

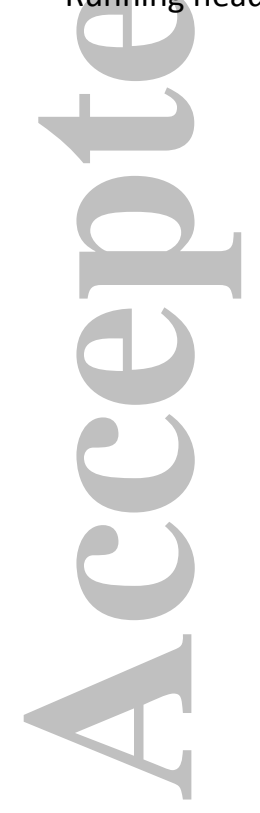




\section{Abstract}

Background/Aim: Transcutaneous electrical stimulation (TES) for 1-2 months has produced some improvement in treatment-resistant slow-transit constipation (STC) in children. Optimal parameters for treatment are not known. It is possible that more improvement would occur with stimulation for longer. This study examined the effectiveness of stimulation for 6 months.

Methods: Children with STC confirmed by nuclear transit study (NTS) were enrolled prospectively. All had chronic constipation for $>2$ years and had failed medical treatment. TES was performed for 1 hour/day for 6 months using the INF 4160 (Fuji Dynamics) portable stimulator and $4 \mathrm{~cm} \times 4 \mathrm{~cm}$ electrodes near the belly button and on the back. Families kept bowel diaries and completed PEDSQLCore QOL (4.0) questionnaires before and at end of treatment.

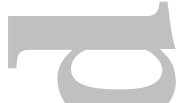

Results:

Sixty-two children (34F; 7yr, 2-16yr) with STC were studied. Defecation frequency increased in $57 / 62(91 \%$, mean \pm SEM pre $1.49 \pm 0.20$ vs. post $3.25 \pm 0.25$ defecation/week, $p<0.0001$ ) with the number with $\geq 3 B A$ increasing from 6 to 37 (10\% to 59\%). Soiling frequency decreased from 4.8 to 1.1 days/wk. ( $p<0.001$ ). Abdominal pain decreased from 1.7 to 0.3 days/wk. $(<0.0001)$, and spontaneous urge to defecate improved. Quality of life $(p<0.01)$, mean transit index and gastric emptying on NTS improved $(p<0.005)$.

Conclusion: Treatment-resistant STC responds to TES using interferential current across the abdomen when given daily for many months. Battery operated stimulators allowed stimulation at home for an hour each day. Stimulation for 6 months produced clinically significant improvement in defecation frequency, soiling, abdominal pain, urge to defecate and quality of life in half of these chronic patients. 

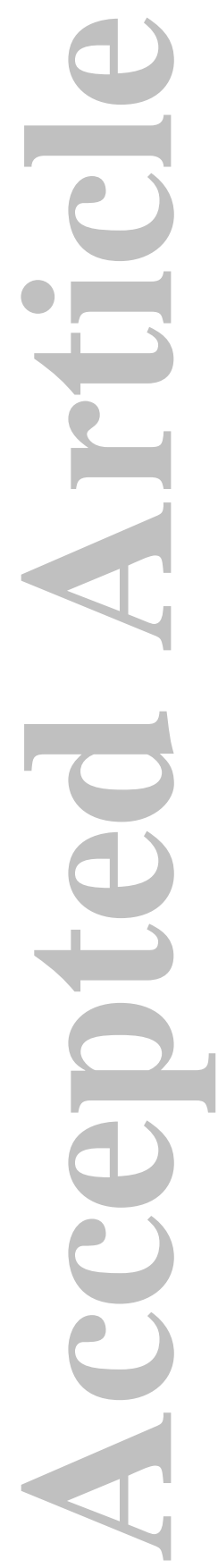

Neuromodulation Proof

This article is protected by copyright. All rights reserved. 


\section{Introduction}

Slow-transit constipation (STC) is a form of chronic constipation associated with a decreased frequency of peristalsis in the colon, and was first identified in children in the 1990's with the introduction of whole bowel transit studies $(1,2)$. The pathophysiology of STC has been documented (3), highlighting the differences between paediatric and adult presentations (4). Up to $10 \%$ of children presenting with chronic intractable constipation have STC.

(10\%

One promising new treatment for STC is transcutaneous electrical stimulation (TES), using interferential current and 4 electrodes on the skin over the abdomen and lumbar region. (5). In a randomised controlled trial (RCT), 46 children were randomised to sham or active treatment supervised by a physiotherapist for 20 mins, 3 times a week, for a month. Colonic motility was slightly faster, however, there was no change in defecation frequency, suggesting that the treatment may have been insufficient to overcome the clinical problem. Following the RCT, a small cohort of the patients (11 children), were treated at home with a battery-operated, portable interferential device. With daily treatment for one hour, for a further 2 months, 9 out of the 11 children experienced an increase in defecation frequency (6). We followed this by a larger cohort study to determine the training required for clinicians to successfully train parents to perform home stimulation. Training in 6 patients was followed by treatment of 32 patients for 3-6 months and showed improvement (7). In this study, we added another 30 patients and present the outcome data for the combined group with all patients treated for 6 months. We studied common symptoms: defecation frequency, soiling frequency, abdominal pain, and urge to defecate. As our institute performs nuclear transit scintigraphy (NTS) $(8,9)$, we measured gastric emptying, and whole bowel transit, before and after treatment. We also determined quality of life using the PedsQL Core scale and the short Gastrointestinal symptom score. This larger cohort showed significant improvements in symptoms. 


\section{Methods:}

After ethical approval (HREC 26173, 300059A, 30116A) from the institutional Human Ethics Committee, children were enrolled prospectively over 3 years (2009-11). Inclusion criteria specified that the children had chronic constipation and soiling for $\geq 2$ years and had failed to respond to medical treatment (diet, behaviour modification, laxatives/enemas) and had been investigated by NTS, where a diagnosis of STC was made as described previously (9-11). The specific criteria on NTS were that there was $\geq 40 \%$ of tracer retained in the transverse colon at 24 hours and/or $\geq 30 \%$ at 48 hours, or a mean geometric centre of $\leq 3.0$ and/or $\leq 4.2$ at 24 and 48 hours, respectively. Exclusion criteria were patients with ventriculoperitoneal shunts or cardiac pacemakers, to avoid potential effects of electrical interference.

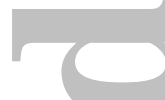

Following training by a continence physiotherapist on the principles and use of TES, the first author piloted the supervision of home TES on 6 patients to ensure correct use of the machine and collection of meaningful data (7). The pilot study patients are not included in the results presented here, but were important for the clinician to understand the safe and effective use of the device in the home environment under parental control, and how to motivate families to record and return their bowel-function diary. After this, parents of children less than 8 years and older children (8-18 years) were trained to use the 9-volt, battery-operated, rechargeable and portable interferential stimulator (INF4160, Fuji Dynamics Ltd, Kowloon, Hong Kong) by the first author, and provided with instruction sheets on how to use the machine at home. Stimulation was performed at home for 1 hour daily for 6 months, with frequent contacts (phone/email) to ensure treatment compliance and recording of the bowel function diary. The battery was recharged each night to ensure consistent delivery of current for the one hour session. 
Two self-adhesive $(4 \times 4 \mathrm{~cm})$ electrodes were placed on the anterior abdominal wall at the level of the umbilicus, and 2 other electrodes placed on the back between T9 and L2 spinal segments on either side, as described previously $(7,12)$. Interferential current was delivered by a $4 \mathrm{kHz}$ carrier frequency, a beat frequency of 80 to $160 \mathrm{~Hz}$ at a current of $\leq 33 \mathrm{~mA}$ (12), with the current turned up so children could feel comfortable tingling during treatment. They were instructed to report any abnormal sensation or adverse event to the investigators.

A bowel function diary was recorded for one month before treatment and continued daily throughout treatment. Parents and children completed PEDSQL 4.0 Core module questionnaires before and at the end of TES treatment. Families were instructed to fill in the bowel diary (recording soiling, defecation frequency, abdominal pain, urge to defecate and laxative use) in a structured manner. The primary outcome was defecation frequency (bowel actions/day). Secondary outcomes included soiling, abdominal pain, sensation or urge to defecate, laxative use and gastrointestinal transit. Soiling and abdominal pain were measured as days/week with symptom occurrence. Urge to defecate was measured using a visual analogue scale. The following changes were defined as an improvement: 1 ) defecation frequency $\geq 3 / \mathrm{wk}$. (for those who started $<3 \mathrm{BA} / \mathrm{wk}$. at baseline); 2 ) reduced frequencies of soiling and abdominal pain (measured by days/wk. of occurrence); 3) reduced laxative use; 4) increased PEDSQL scores, and 5) faster colonic transit measured by NTS.

The effects of TES on STC symptoms were evaluated statistically by paired t-test (for parametric measures and signed-rank tests (for non-parametric variables). The statistical package used was STATA 12 and GraphPad Prism with $p<0.05$ was considered significant.

\section{Results}


Sixty-two children with STC (34F, mean age 7 years, range 2-16 years) were enrolled and successfully completed 6 months TES (with preliminary results of the first 32 patients already published (7)). All had bowel diaries completed before and at the end of TES treatment. Demographics are shown in Table 1. Thirty five children had constipation symptoms beginning at less than 1 year of age, with a Table 1 specific diagnosis of STC confirmed at the age of 6-7 years after a NTS. Half had soft rather than hard stool, and 56 had $<3$ bowel actions (BA)/week (when not using laxatives). Soiling occurred on $4.8 \pm 2.7$ days/week (mean, SD) and abdominal pain on $1.7 \pm 1.8$ days/week. Only 2 children were not using laxatives before the study, and a wide range of laxatives were used by the other 60 children. A family history of constipation occurred in half.

There was a significant increase in defecation frequency (bowel actions $(B A) /$ week, mean $\pm S D$, pre $1.5 \pm 0.1 .6$ vs. post $3.3 \pm 2.0, p<0.0001$, paired t-test, Fig. 1$)$ in $58 / 62(94 \%)$ children, and the number of children with defecation frequency in the normal range of $\geq 3 \mathrm{BA} /$ week increased significantly 6 to $37\left(10 \%\right.$ to $\left.60 \%, \chi^{2}, p<0.0001\right)$. Twelve $(19 \%)$ increased by $3-7 \mathrm{BA} / \mathrm{wk}$. and $46(74 \%)$ increased by $<3$ $\mathrm{BA} / \mathrm{wk}$. (0.25-3.00). After TES, soiling decreased with children reducing 1 to 7 episodes of soiling/ week, and the mean soiling frequency reducing significantly from 4.8 to 1.1 days/week with soiling (paired t-test, $p<0.0001$, Fig 1). Soiling frequency was unchanged in $1 \mathrm{child}$, and 7 did not have soiling before or during TES. There was no abdominal pain in $23 / 62$ children before or during the treatment period. For the 39 with abdominal pain, the number of days with pain reduced from median (range) 2 (0.25-7) to 0 (0-2) days/week (Wilcoxin matched pairs, $p<0.0001$ ).

Before TES, children had either no urge or a weak urge to defecate (Fig.2). After TES all had at least some urge, with most having a moderate or strong urge to defecate. Before TES, 60 (97\%) children used laxatives, while after TES one quarter of the children stopped all laxatives and half of them reduced laxatives (Fig.3). 
Quality of life scores using the PEDSQL Core module showed a significant improvement in childreported and parent-reported scores in the total score $(p<0.01)$ as well as both physical $(p<0.01)$ and psychosocial $(p<0.01)$ categories. Overall, $75 \%$ of families reported an increase in QOL scores of $\geq 10$ units after TES (Fig.4).

Forty-eight children had NTS done at RCH both before and after TES. There was a small but significant improvement in the mean GIT transit index from 10.8 to 11.6 ( $p=0.004$, higher value is faster transit). In the 15/48 children with delayed gastric emptying as well as STC there was a significant improvement in gastric emptying after TES ( $p=0.01$, lower value is faster emptying, Fig.5).

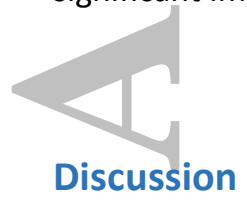

TES given for an hour a day for 6 months produced improvement in at least one symptom (bowel frequency, soiling, abdominal pain) in more than $90 \%$ of children. Defecation frequency increased in table 2 nearly all patients, with half increasing from $<3 \mathrm{BA} /$ week into the normal range and $20 \%$ increasing by $>3 \mathrm{BA} / \mathrm{wk}$. The increase in defecation frequency is similar to a study previously reported by our group where patients only received 3 months stimulation (Table 2) (6). Patients in the earlier study started with higher mean $\mathrm{BA} / \mathrm{wk}$. and increased to a higher mean $\mathrm{BA} / \mathrm{wk}$. The percent of patients improving to $>3 \mathrm{BA} / \mathrm{wk}$. was similar. There was a greater proportion patients with a reduction in soiling and a significant reduction in abdominal pain with longer stimulation (Table 2). In the current study, we also measured the urge to defecate and this improved significantly in $95 \%$ and may be another important element of bowel function to assess in children with chronic constipation. The optimal duration for stimulation (minutes each day and for how many days/months) is yet to be determined. 
Quality of life is poor in children with STC, and is equivalent to those with chronic illness like cancer (13). After TES, mean quality of life improved significantly by 10-20 points in both the child-reported and parent-reported assessments. This level of improvement is clinically important, and was better than the results reported in our previous randomised controlled trial, where there was improvement in child-reported quality of life but not in the parent-reported assessment (14). This difference might be due to the longer duration of TES in the current trial (7 hours/week for 6 months vs. 1 hour/week for 1 month).

$+$

As an objective assessment of colonic transit, the NTS showed a small improvement, equivalent to $1 / 4$ of the large bowel at 48 hours. These results are consistent with our previous findings in an RCT (5). Interestingly, TES also sped up delayed gastric emptying. This may be secondary to improvement in constipation feeding back through the gastro-colic reflex, or could be due to a direct effect of the current on gastric motility.

In this study the first author was trained to use the interferential electrical device and families were given a teaching session before taking the device home. Piloting the education and use of the device on 6 patients before the trial enabled successful introduction of the device for home-based TES (15). Problems identified on the use of the device and trouble-shooting were important aspects to ensure appropriate administration of TES at home. Continuous support and frequent contact were also required to monitor and ascertain compliance of treatment (16).

The evidence for the use of interferential current (IFC) to treat bowel disorders is overall weak but growing. While it has been used for over 20 years to treat bladder over-activity (17) and urinary incontinence and to strengthen the pelvic floor (18), it has been used to treat bowel motility disorders for the last 10 years. A number of groups have shown weak positive effects in adults with slow transit constipation (19), functional dyspepsia (20), and irritable bowel syndrome (21), and for 
continence in children with myelomeningocele (a type of spina bifida) (22). In the colon, IFC increased colonic motility, sped up colonic transit, increased the sensation of the urge to defecate, increased defecation frequency and reduced soiling and bloating (23). A major difficulty for treating the viscera, is the problem with measuring changes in response to different frequencies and beat.

Studies similar to those performed by Ward et al (24) on skeletal muscle would be helpful to establish the range of optimal frequencies for muscle contraction, sensory, motor and pain thresholds. Ward et al showed for skeletal muscle, for maximum comfort with low torque, $10 \mathrm{kHz}$ is indicated, while for maximum torque, $1 \mathrm{kHz}$ or less is preferable (24). Discrimination between pain and motor stimulation is maximal at $10 \mathrm{kHz}$. There is nerve fibre firing fatigue when continuous or modulated AC is used, with the effects increasing with frequency (25). Thus carrier frequencies of 2$4 \mathrm{kHz}$, modulated at $50 \mathrm{~Hz}$, are a compromise between comfort and maximum torque production. Above $10 \mathrm{kHz}$ there is reportedly no useful clinical role for IFC in rehabilitation procedures (25). Further studies are required to determine optimal stimulation parameters for the bowel.

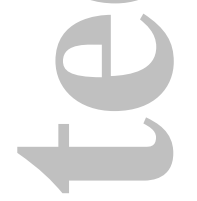

While the stimulation parameters used in our study were similar to those used on bladder that produced diarrhoea as a side effect (26), the mechanism of action of TES on the bowel is still not clear. Potential targets are sensory nerves in the skin, sensory and motor nerves in the spinal cord, sympathetic and parasympathetic nerves, the enteric nerves in the bowel wall or pacemaker cells in the intestine (Interstitial Cells of Cajal), or the intestinal muscle cells (27). In addition, improved circulation might promote improved homeostasis in the bowel.

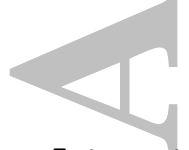

Future studies could also examine the additive effect of using TES with other treatment modalities, such as laxative disimpaction, stool softeners and prokinetics, dietary modification and education about toileting posture to optimise treatment for patients with STC. It may also be useful to examine 
the optimal time for treatment. Since there is a lack of waking patterns in colonic motility in patients with STC (28-33), TES in the morning may be more effective.

\section{Limitations}

This was a prospective study of children with chronic constipation treated with TES daily for 6 months. Patients were their own control but there was no measure of the size of placebo effect. However, as stimulation is felt, it is difficult to provide sham stimulation for a placebo arm. Another limitation is that we do not know the optimal electrical settings of electrical frequency, duration or timing of stimulation. The optimal treatment plan will require further studies to develop.

In conclusion, TES was an effective treatment for about half of the children with otherwise intractable STC. Defecation frequency increased in patients and was associated with decreased soiling, reduced abdominal pain and laxative use, and development of urge to defecate. In addition, it improved gastric emptying in those children with delay. Stimulation was given daily for an hour for 6 months and produced a similar increase in defecation frequency with better improvement in soiling and abdominal pain than treatment for 3 months reported previously by our group. As it is non-invasive, TES could be tried before surgery is considered in children with STC-type chronic treatment-resistant constipation.

\section{Acknowledgements}

We thank Duncan Veysey for performing the transit studies and Prof David Cook for interpretation of the transit studies and diagnosis of STC. A PhD scholarship from the Malaysian Government supported Dr Yee lan Yik. A Senior Research Fellowship from the Australian National Health and Medical Research Council supported Dr Southwell. A preliminary study was published on 32 patients in J Ped Surg in 2012 (J Pediatr Surg. 2012;47(6):1285-90. ) and the data on 62 patients was presented at the International Neuromodulation Society meeting in Berlin in 2012, the Gastroenterology Society of Australia meeting in 2012 and published in abstract form (J 
Gastroenterology and Hepatology. 2012;27(Suppl 4):156) and presented at the Pacific Association of Pediatric Surgeons' meeting in Korea (May 2015).
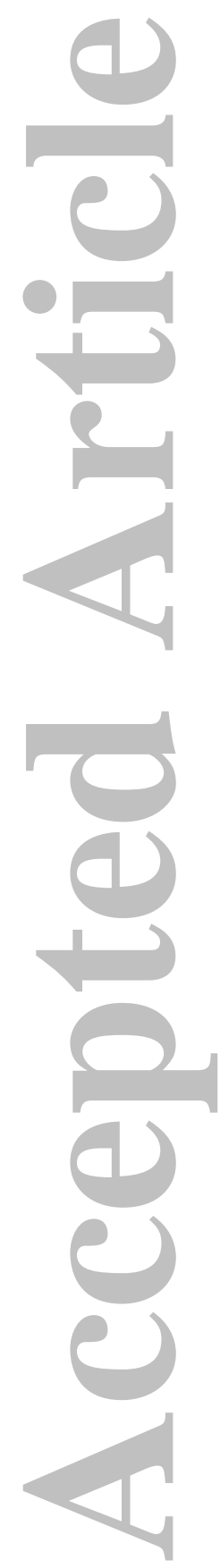
Table 1. Demographics of 62 children with slow-transit constipation before treatment

\begin{tabular}{|c|c|c|}
\hline Demographics (before TES) & $\mathbf{n}$ & $\%$ \\
\hline Female & 34 & 55 \\
\hline Have a family history of constipation & 30 & 48 \\
\hline Delayed meconium passage ( $n$ ) & 12 & 19 \\
\hline Age at onset of constipation $<12$ months ( $n$ ) & 35 & 56 \\
\hline Other medical conditions & 17 & 27 \\
\hline Number using laxatives & 60 & 97 \\
\hline Number using $>2$ subclasses of laxative & 17 & 27 \\
\hline Number with <3 Bowel action/week & 56 & 90 \\
\hline Number with small stool size & 23 & 37 \\
\hline & Mean & SD \\
\hline Age at STC diagnosis (years) & 6.8 & 4.1 \\
\hline $\begin{array}{l}\text { Duration with constipation before STC diagnosis } \\
\text { (years) }\end{array}$ & 5.4 & 3.4 \\
\hline Average number of bowel actions/week & 1.5 & 1.6 \\
\hline Number of days with soiling per week & 4.8 & 2.4 \\
\hline Number of days per week with abdominal pain & 1.7 & 1.8 \\
\hline $\mathrm{BMI}\left(\mathrm{kg} / \mathrm{m}^{2}\right)$ & 17.9 & 3.6 \\
\hline
\end{tabular}


Table 2: Comparison of results in this study and in Ismail et al 2009 (6).

\begin{tabular}{|c|c|c|}
\hline Study & Ismail 2009 & This study \\
\hline $\begin{array}{l}n \\
\text { Months of TES }\end{array}$ & $\begin{array}{l}11 \\
3\end{array}$ & $\begin{array}{l}62 \\
6\end{array}$ \\
\hline $\begin{array}{l}\text { Bowel actions (BA)/wk. } \\
\text { number who increased BA/wk. } \\
\% \text { who increased BA/wk. } \\
\text { BA /wk. pre, mean (SD) } \\
\text { BA /wk. post, mean (SD) } \\
\text { p } \\
\% \text { with }<3 \text { BA/wk. pre } \\
\% \text { with }<3 \text { BA/wk. post }\end{array}$ & $\begin{array}{c}9 / 11 \\
82 \\
2.5(2.1) \\
6.7(4.4) \\
0.008 \\
45 \\
100\end{array}$ & $\begin{array}{c}58 / 62 \\
94 \\
1.5(1.6) \\
3.3(2.0) \\
<0.0001 \\
10 \\
60 \\
<0.0001\end{array}$ \\
\hline $\begin{array}{l}\text { Soiling } \\
\% \text { with soiling pre } \\
\% \text { with soiling post } \\
\text { soiling pre, mean (SD) } \\
\text { Soiling post, mean (SD) } \\
p\end{array}$ & $\begin{array}{c}55 \\
64 \\
3.8(1.6) \\
1.1(0.5) \\
0.1\end{array}$ & $\begin{array}{c}89 \\
2 \\
4.8(2.4) \\
1.1(1.6) \\
<0.001\end{array}$ \\
\hline $\begin{array}{l}\text { Abdominal Pain } \\
\% \text { with pain pre } \\
\% \text { with pain post } \\
\text { Pain pre, mean (SD) } \\
\text { Pain post, mean (SD) } \\
\text { p }\end{array}$ & $\begin{array}{c}36 \\
36 \\
0.97(1.8) \\
1.03(2.0) \\
0.7\end{array}$ & $\begin{array}{c}63 \\
23 \\
2.7(1.5) \\
0.5(0.7) \\
<0.001\end{array}$ \\
\hline
\end{tabular}




\section{References}

1. Benninga MA, Buller HA, Staalman CR, Gubler FM. Defaecation disorders in children, colonic transit time versus the Barr-score. Eur J Pediatr. 1995;154:277-84.

2. Benninga MA, Buller HA, Tytgat GNJ, Akkermans LMA, Bossuyt PM, Taminiau JA. Colonic transit time in constipated children: does pediatric slow-transit constipation exist? Journal of Pediatric Gastroenterology and Nutrition. 1996;23:241-51.

3. Shin YM, Southwell BR, Stanton MP, Hutson JM. Signs and symptoms of slow-transit constipation versus functional retention. J Pediatr Surg. 2002;37(12):1762-5.

4. Hutson JM, Dughetti L, Stathopoulos L, Southwell BR. Transabdominal electrical stimulation (TES) for the treatment of slow-transit constipation (STC). Pediatr Surg Int. 2015.

5. Clarke MC, Chase JW, Gibb S, Robertson VJ, Catto-Smith A, Hutson JM, et al. Decreased colonic transit time after transcutaneous interferential electrical stimulation in children with slow transit constipation. J Pediatr Surg. 2009;44(2):408-12.

6. Ismail KA, Chase J, Gibb S, Clarke M, Catto-Smith AG, Robertson VJ, et al. Daily transabdominal electrical stimulation at home increased defecation in children with slow-transit constipation: a pilot study. J Pediatr Surg. 2009;44(12):2388-92.

7. Yik YI, Ismail KA, Hutson JM, Southwell BR. Home transcutaneous electrical stimulation to treat children with slow-transit constipation. Journal of Pediatric Surgery. 2012;47(6):1285-90.

8. Yik YI, Cook DJ, Veysey DM, Rutkowski SJ, Tudball CF, King BS, et al. Targeting the causes of intractable chronic constipation in children: The nuclear transit study (NTS). In: Singh N, editor. Radioisotopes- Applications in Bio-medical Science: Intech Open Access; 2011. p. 305-20.

9. Sutcliffe JR, King SK, Hutson JM, Cook DJ, Southwell BR. Gastrointestinal transit in children with chronic idiopathic constipation. Pediatr Surg Int. 2009;25(6):465-72.

10. Cook BJ, Lim E, Cook D, Hughes J, Chow CW, Stanton MP, et al. Radionuclear transit to assess sites of delay in large bowel transit in children with chronic idiopathic constipation. J Pediatr Surg. 2005;40(3):478-83.

11. Southwell BR, Clarke MC, Sutcliffe J, Hutson JM. Colonic transit studies: normal values for adults and children with comparison of radiological and scintigraphic methods. Pediatr Surg Int. 2009;25(7):559-72.

12. Chase J, Robertson VJ, Southwell B, Hutson J, Gibb S. Pilot study using transcutaneous electrical stimulation (interferential current) to treat chronic treatment-resistant constipation and soiling in children. J Gastroenterol Hepatol. 2005;20(7):1054-61.

13. Clarke MC, Chow CS, Chase JW, Gibb S, Hutson JM, Southwell BR. Quality of life in children with slow transit constipation. J Pediatr Surg. 2008;43(2):320-4.

14. Clarke MC, Chase JW, Gibb S, Hutson JM, Southwell BR. Improvement of quality of life in children with slow transit constipation after treatment with transcutaneous electrical stimulation. J Pediatr Surg. 2009;44(6):1268-72; discussion 72.

15. Yik YI, Ismail KA, Hutson JM, Southwell BR. Home transcutaneous electrical stimulation to treat children with slow-transit constipation. J Pediatr Surg. 2012;47(6):1285-90.

16. Feng Tan AY, Black D, Medwyn Hutson J, Southwell BR. Application Failure Mode and Effects Analysis Reveals Failure Modes for Interferential Stimulation Therapy in Treating Chronic Constipation. J Med Device. 2015;9(4):041008-.

17. Hagstroem S, Mahler B, Madsen B, Djurhuus JC, Rittig S. Transcutaneous electrical nerve stimulation for refractory daytime urinary urge incontinence. J Urol. 2009;182(4 Suppl):2072-8. 18. Hosker G, Cody JD, Norton CC. Electrical stimulation for faecal incontinence in adults. Cochrane database of systematic reviews (Online). 2007(3):CD001310.

19. Yang Y, Yim J, Choi W, Lee S. Improving slow-transit constipation with transcutaneous electrical stimulation in women: A randomized, comparative study. Women Health. 2016:1-14. 
20. Koklu S, Koklu G, Ozguclu E, Kayani GU, Akbal E, Hascelik Z. Clinical trial: interferential electric stimulation in functional dyspepsia patients - a prospective randomized study. Aliment Pharmacol Ther. 2010;31(9):961-8.

21. Coban S, Akbal E, Koklu S, Koklu G, Ulasli MA, Erkec S, et al. Clinical Trial: Transcutaneous Interferential Electrical Stimulation in Individuals with Irritable Bowel Syndrome - A Prospective Double-Blind Randomized Study. Digestion. 2012;86(2):86-93.

22. Hutson JM, Dughetti L, Stathopoulos L, Southwell BR. Transabdominal electrical stimulation (TES) for the treatment of slow-transit constipation (STC). Pediatr Surg Int. 2015;31(5):445-51.

23. Southwell BR, Yik YI, Tan A, Jordan-Ely J, Hutson JM. Transcutaneus Electrical Stimulation over the Belly in Slow-Transit Constipation. In: Núñez R, Fabbro MA, editors. Constipation in Children: Diagnosis and Treatment. Hauppauge NY, USA: Nova Publisher; 2013. p. 299-320, (https://www.novapublishers.com/catalog/product info.php?products id=44336). .

24. Ward AR, Robertson VJ. Variation in torque production with frequency using medium frequency alternating current. Arch Phys Med Rehabil. 1998;79(11):1399-404.

25. Ward AR, Robertson VJ. Variation in motor threshold with frequency using $\mathrm{kHz}$ frequency alternating current. Muscle Nerve. 2001;24(10):1303-11.

26. Emmerson CA. A preliminary study of the effect of interferential therapy on detrusor instability in patients with multiple sclerosis. Aust J Physiother. 1987;33:64-5.

27. Southwell BR, King SK, Hutson JM. Chronic constipation in children: organic disorders are a major cause. J Paediatr Child Health. 2005;41(1-2):1-15.

28. Rao SS, Sadeghi P, Beaty J, Kavlock R, Ackerson K. Ambulatory 24-h colonic manometry in healthy humans. Am J Physiol Gastrointest Liver Physiol. 2001;280(4):G629-39.

29. Bassotti G, de Roberto G, Sediari L, Morelli A. Colonic motility studies in severe chronic constipation: an organic approach to a functional problem. Tech Coloproctol. 2004;8(3):147-50. 30. Bassotti G, de Roberto G, Castellani D, Sediari L, Morelli A. Normal aspects of colorectal motility and abnormalities in slow transit constipation. World J Gastroenterol. 2005;11(18):2691-6. 31. Rao SS, Ozturk R, Laine L. Clinical utility of diagnostic tests for constipation in adults: a systematic review. Am J Gastroenterol. 2005;100(7):1605-15.

32. Zhang WQ, Yan GZ, Ye DD, Chen CW. Simultaneous assessment of the intraluminal pressure and transit time of the colon using a telemetry technique. Physiol Meas. 2007;28(2):141-8.

33. Rao SS, Singh S, Mudipalli R. Day-to-day reproducibility of prolonged ambulatory colonic manometry in healthy subjects. Neurogastroenterol Motil. 2010;22(6):640-e178.

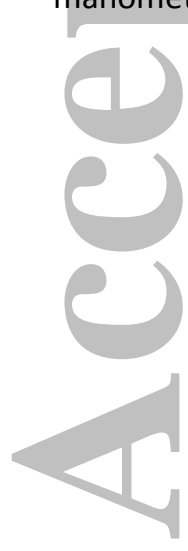


Table 1. Demographics of 62 children with slow-transit constipation before treatment

\begin{tabular}{|l|c|c|}
\hline \multicolumn{1}{|c|}{ Demographics (before TES) } & $\mathbf{n}$ & $\%$ \\
\hline Female & 34 & 55 \\
Have a family history of constipation & 30 & 48 \\
Delayed meconium passage ( $\mathbf{n}$ ) & 12 & 19 \\
Age at onset of constipation < 12 months ( $\mathbf{n}$ ) & 35 & 56 \\
Other medical conditions & 17 & 27 \\
Number using laxatives & 60 & 97 \\
Number using > 2 subclasses of laxative & 17 & 27 \\
Number with <3 Bowel action/week & 56 & 90 \\
Number with small stool size & 23 & 37 \\
\hline & Mean & SEM \\
\hline Age at STC diagnosis (years) & 6.80 & 4.1 \\
Duration with constipation before STC diagnosis & 5.40 & 3.4 \\
(years) & 1.50 & 1.5 \\
Average number of bowel actions/week & 4.80 & 2.7 \\
Number of days with soiling per week & 1.70 & 1.8 \\
Number of days per week with abdominal pain & 17.90 & 3.6 \\
\hline BMI (kg/m ${ }^{2}$ ) & & \\
\hline
\end{tabular}


Table 2: Comparison of results in this study and in Ismail et al 2009 (6).

\begin{tabular}{|c|c|c|}
\hline Study & Ismail 2009 & This study \\
\hline $\begin{array}{c}n \\
\text { Months of TES }\end{array}$ & $\begin{array}{c}11 \\
3\end{array}$ & $\begin{array}{c}62 \\
6 \\
\end{array}$ \\
\hline $\begin{array}{c}\text { Bowel actions (BA)/wk } \\
\text { number who increased BA/wk } \\
\% \text { who increased BA/wk } \\
\text { BA /wk pre, mean (SD) } \\
\text { BA /wk post, mean (SD) } \\
p \\
\% \text { with }<3 \text { BA/wk pre } \\
\% \text { with }<3 \text { BA/wk post }\end{array}$ & $\begin{array}{c}9 / 11 \\
82 \\
2.5(2.1) \\
6.7(4.4) \\
0.008 \\
45 \\
100\end{array}$ & $\begin{array}{c}58 / 62 \\
94 \\
1.5(1.6) \\
3.2(2.0) \\
<0.0001 \\
10 \\
60 \\
<0.0001\end{array}$ \\
\hline $\begin{array}{l}\text { Soiling } \\
\% \text { with soiling pre } \\
\% \text { with soiling post } \\
\text { soiling pre, mean (SD) } \\
\text { Soiling post,mean (SD) } \\
\mathrm{p}\end{array}$ & $\begin{array}{c}55 \\
64 \\
3.8(1.6) \\
1.1(0.5) \\
0.1 \\
\end{array}$ & $\begin{array}{c}89 \\
2 \\
4.8(2.4) \\
1.1(1.6) \\
<0.001 \\
\end{array}$ \\
\hline $\begin{array}{l}\text { Abdominal Pain } \\
\% \text { with pain pre } \\
\% \text { with pain post } \\
\text { Pain pre, mean (SD) } \\
\text { Pain post, mean (SD) } \\
\mathrm{p}\end{array}$ & $\begin{array}{c}36 \\
36 \\
0.97(1.8) \\
1.03(2.0) \\
0.7 \\
\end{array}$ & $\begin{array}{c}63 \\
23 \\
2.7(1.5) \\
0.5(0.7) \\
<0.001 \\
\end{array}$ \\
\hline
\end{tabular}




\section{A. Defecation B. Soiling}

\section{Abd Pain}
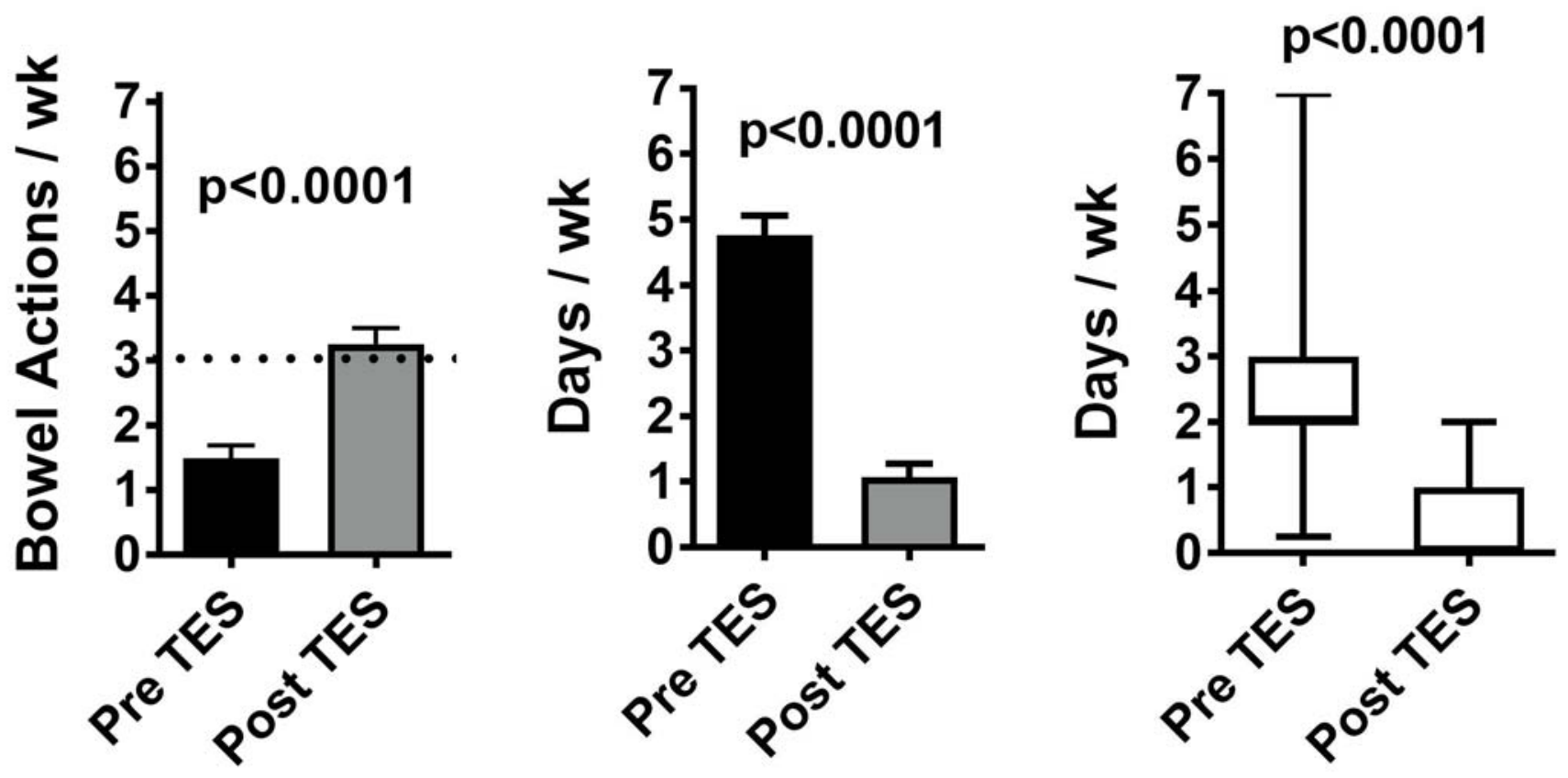

Neuromodulation Proof

This article is protected by copyright. All rights reserved. 
Page 21 of 25

Nergemodulation Brooffecate

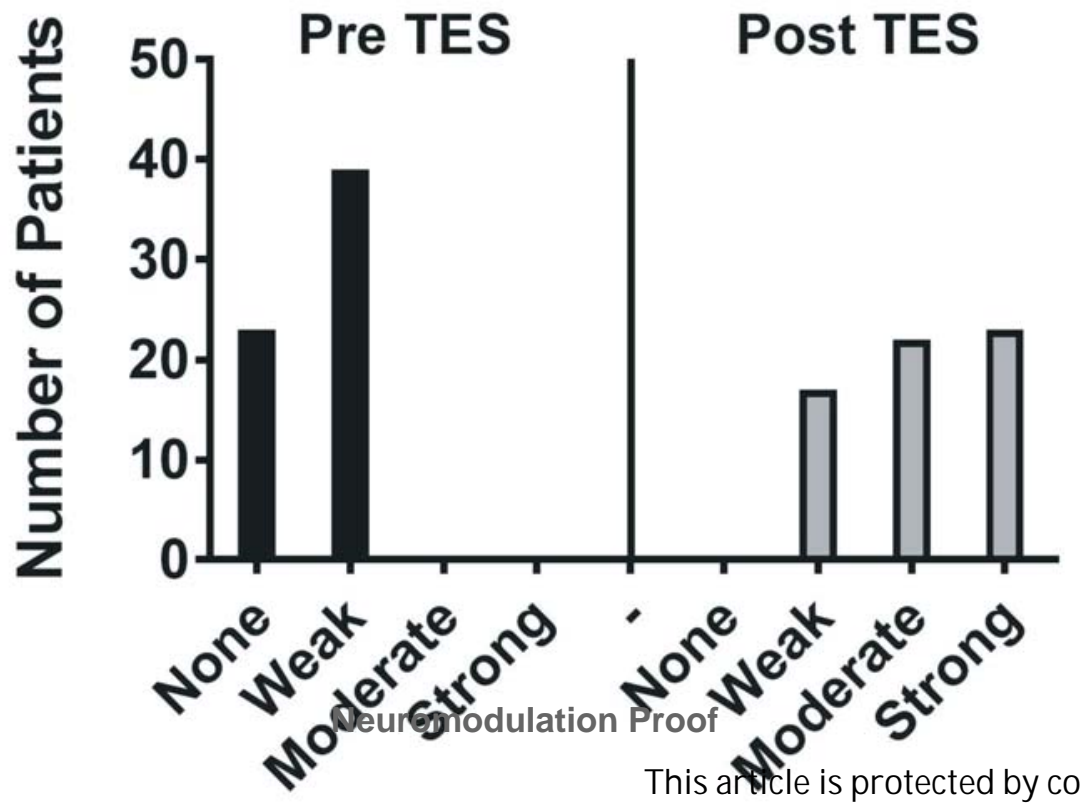




\section{Laxative Use}

م

60

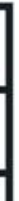

to

30 .

๖ั

อ

50

40 -

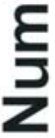

20 .

10 .

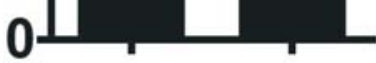

Reduced

Stopped

Continued

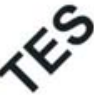

¿ Neurologódulation Proof

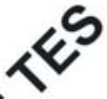



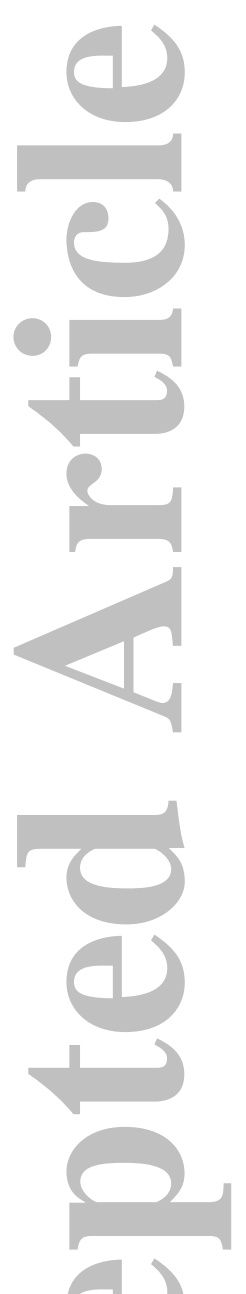

$<5$ Yrs Parent-rep

5-18 Yrs Child-rep

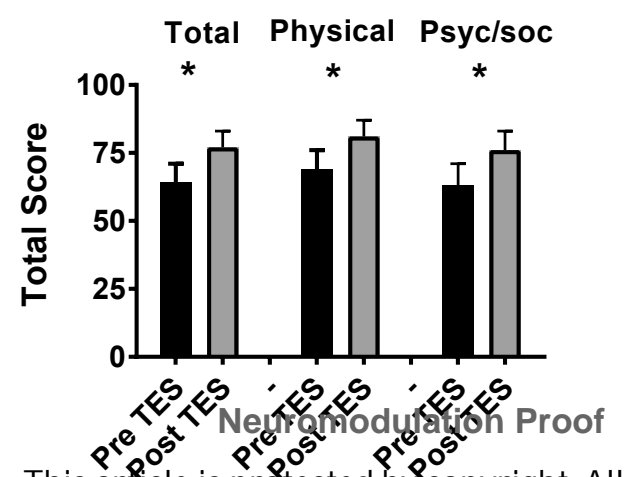

5-18 Yrs Parent-rep

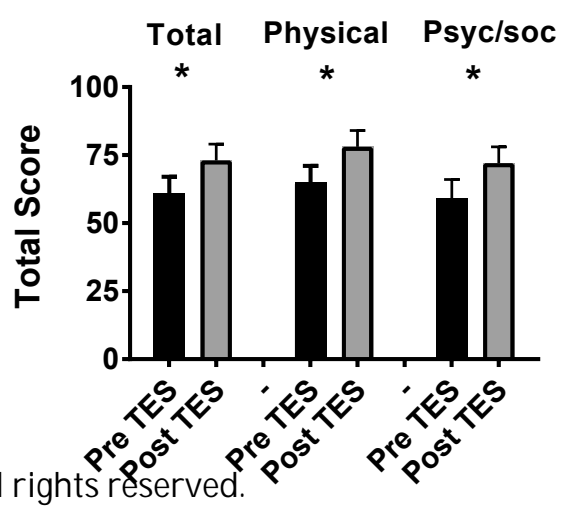




\section{GIT Index}
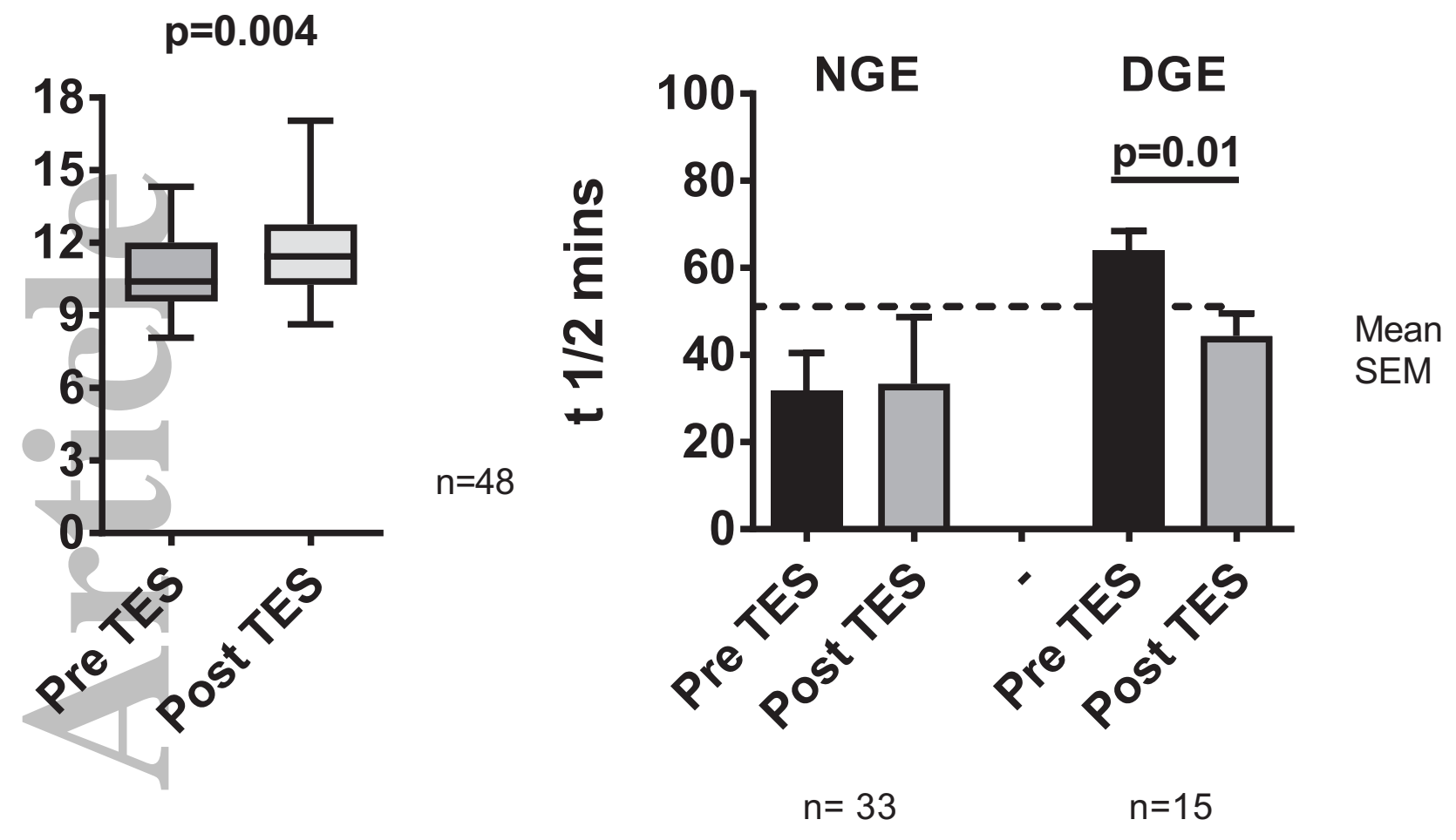


\section{Figure Legend}

Figure 1: $\quad$ A) Defecation frequency, B) soiling frequency and C) Abdominal pain in children with

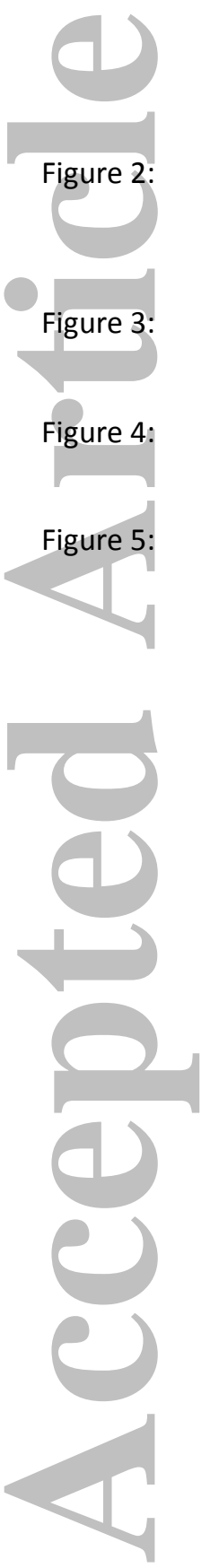
STC before and after transcutaneous electrical stimulation (TES). wk=week, A and Bmean and standard error of mean, $n=62$, paired $t$-test. C- median and quantiles, $\mathrm{n}=39$, Wilcoxin paired signed rank test.

Urge to defecate in children with STC before and after TES. $\mathrm{N}=62$. A visual analogue scale was used to score Urge to Defecate: $0=$ no urge, 1 to $3=$ weak, 4 to $6=$ moderate, 7 to $10=$ strong). Number of patients with each level of urge is shown.

Laxative use in children with STC before and after TES. N=60. Two children had stopped laxatives before start of TES.

PedsQL scores before and after TES. Mean and standard error of mean, paired t-test. $n=23$ for $\leq 4$ years and $n=39$ for $5-18$ years.

A) GIT Index and B) Gastric emptying (GE) in children with STC before and after TES. A) The GIT Index is the sum of the GC for each time point (6, 24, 30 and 48 hours). A higher value represents faster transit, $n=48$. B) For $G E, 33$ had normal $G E$, with no change with TES. Fifteen had delayed GE before TES, and GE emptying improved to less than $\mathrm{t} 1 / 2=50$ mins (upper limit of normal, $\mathrm{p}=0.01$ ). 


\section{University Library}

\section{- M M N E R VA A gateway to Melbourne's research publications}

Minerva Access is the Institutional Repository of The University of Melbourne

Author/s:

Yik, Yl;Hutson, J;Southwell, B

Title:

Home-Based Transabdominal Interferential Electrical Stimulation for Six Months Improves Paediatric Slow Transit Constipation (STC)

Date:

2018-10-01

\section{Citation:}

Yik, Y. I., Hutson, J. \& Southwell, B. (2018). Home-Based Transabdominal Interferential Electrical Stimulation for Six Months Improves Paediatric Slow Transit Constipation (STC). NEUROMODULATION, 21 (7), pp.676-681. https://doi.org/10.1111/ner.12734.

Persistent Link:

http://hdl.handle.net/11343/293903 